\title{
THE ROLE OF COMPUTER SYSTEMS IN THE MANAGEMENT OF HOTELS IN VELIKO TARNOVO REGION, BULGARIA
}

\author{
Olga MANCHEVA-ALI, Vanya DIMITROVA
}

\author{
"Vasil Levski" National Military University, Veliko Tarnovo, Bulgaria \\ olga_mancheva@abv.bg
}

\begin{abstract}
This study presents the essence, importance and role of hotel computer systems used in Veliko Tarnovo region. The attached questionnaire presents a method of analyzing systems and their role in the management process. The study shows the most used local systems, their advantages and disadvantages and possible steps and recommendations for the improvement of their effectiveness.
\end{abstract}

\section{Keywords: management, software, automation of the activities}

\section{Introduction}

In today's fast-paced life, searching for opportunities to relax, people more and more look for the services of hotels, which are in the right place and time for them. Hotel software plays a huge role in hotel business in order to meet the increasing requirements of the customers.

Hotel management software is defined as systems meant to automate the business processes in the organization. Although there are various definitions in that aspect, for the purposes of our research, we refer to А. G. Titorenко's definition. According to him, the automated information technologies are an aggregation of methods and resources which accomplish operations, connected to the information flows and their application in the enterprise. [4]

Generally speaking, hotel management software is an applied, module-based computer program, whose purpose is to collect, store, transmit, process and analyze data in order to receive the information, necessary for the provision of a high- quality, efficient service to the tourist. It is also a successful management tool in the modern, high-tech hotel. The systems are directed towards both sides in the process of communication: hotel - tourist and hotel - tourist - middleman - tourist. These systems assist their interaction with speed, precision and are very effective in terms of time, resources, and management of the hotel processes. [1]

Currently, there are many Bulgarian and foreign manufacturers, specializing strictly in creating local hotel systems with different technical and technological characteristics. This allows the hoteliers to choose a product which corresponds to the specifics of their facility and which is suitable for the volume of work they do. Without neglecting any of the systems, our goal is to examine and analyze the specifics of hotel management software and its impact on hotel business management. 
1. Hotel management software - specifics and influence on management processes

V. Todoriev defines hotel computer systems as a possibility for the manager to exercise control over all the activities by modulating the processes, cycles and the separate phases of the hotel's operations, connected with the actual marketing and management; as well as controlling the activities connected with the storage space, pricing, accounting, trading, dining and recreation facilities, hotel household, additional services etc. The most common modules are: [3]

configuration of the hotel base;

$>$ reservations;

$>$ room allocation;

$>$ contracts;

$>$ hotel household;

$>$ statistics;

$>$ dining and recreation;

$>$ nationality of the guests etc.
The hotel management software is a corporate product, offering functions, specific to the technological cycle and activities in the hotel enterprise. It is built of modules for planning, organizing, managing, conducting and control over the activities in the hotel. These modules provide the hotel management with a wide variety of professional options, offer optimal solutions for every process, contribute to the development of the technology and maintain high standards of service. There are many Bulgarian and foreign companies, specialized in the production of hotel systems with different technical and technological characteristics, which allows hoteliers to choose a particular product, corresponding to the needs of the specific hotel and to the amount of work done there.

Figure 1 shows the users of the local hotel system and the collaboration between them.

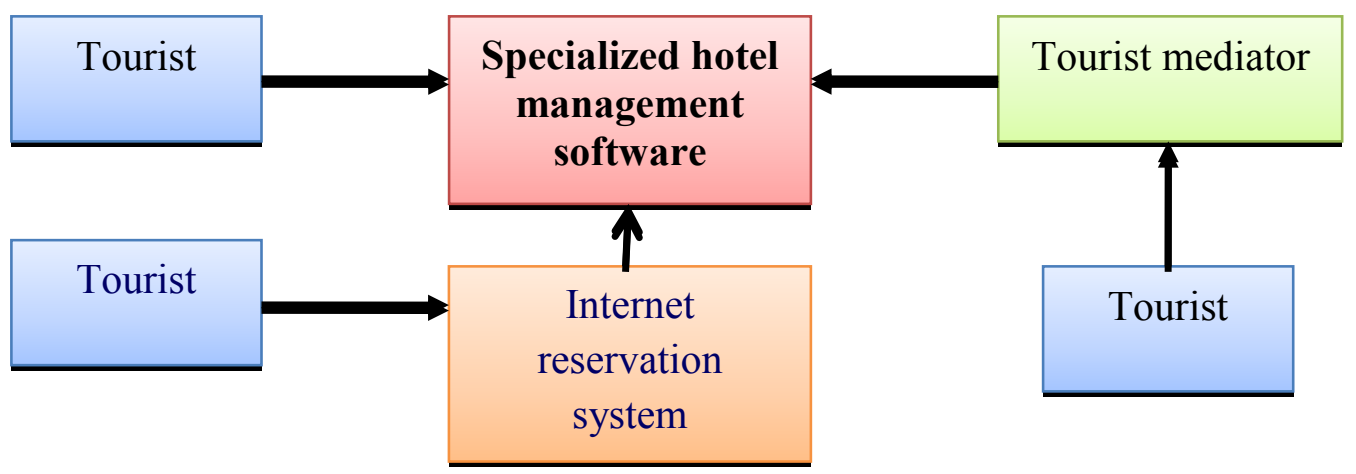

Figure 1. Hotel management software and its users (original figure)

It is evident that the system works with the tourists directly, indirectly and trough the mediation of a tour operator or a tour agent as well as through an internet reservation system. The connection is easy, accessible and reduces the possibility for information mistakes and inaccuracies in the communication to the minimum.

\section{Types of hotel management software}

In order to define the influence of the specialized computer programs in the hotel business and their impact on management processes and because of the lack of precise and clear differentiation between the different types of hotel management software, we suggest the following classification, where the technological 
capacities of the systems are of great importance (Fig.1)

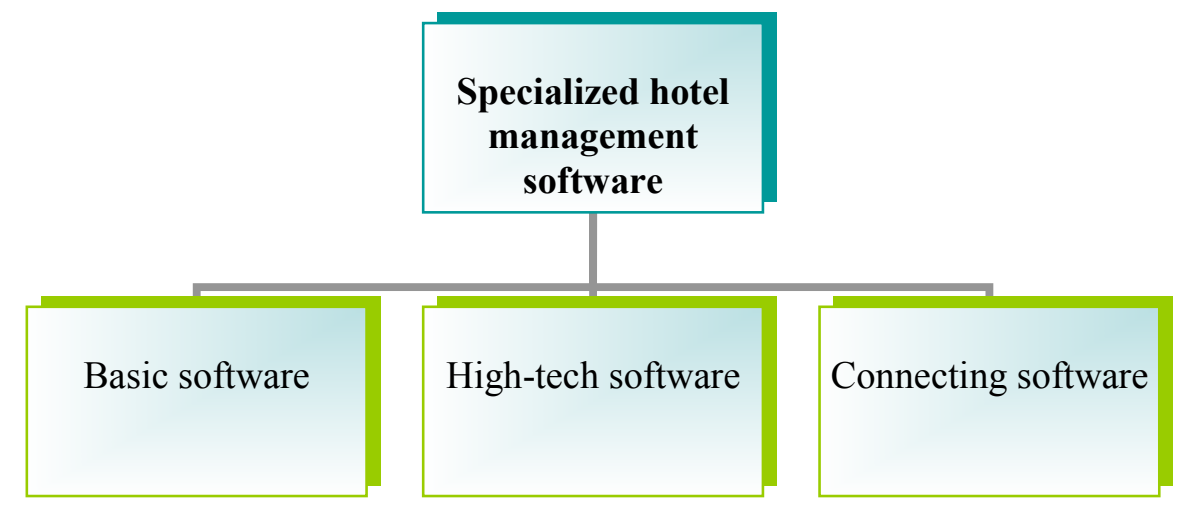

Figure 2. Types of specialized hotel management software (original figure)

Here is a short description of the listed software:

Basic software - Including hotel software which only has basic functions for the management of the hotel - reservations, accommodation, and payment. This software cannot communicate with other departments of the hotel (restaurant, SPA and wellness center, telephone system) and is completely independent. It is not flexible and is often not functionally consistent. This software is preferred by hotels with small capacity and low rating (chiefly, with up to 30 beds, 1 or 2 stars). The products are cheap and often not capable of working with newer computer versions. Their manufacturers do not create updates to the existing software, which means that the software or the connected module do not function or are inapplicable when there is a newer version of the office package.

The basic software has favorable influence on the management processes, assisting in the organization of some of the activities and processes in the hotel. The price of the products is low and the managers do not need to invest a lot in their purchase and implementation. Through their usage, the activity in the hotel can be defined as semiautomatic i.e. an activity depending on human resources on all levels.
High-tech software - These are software applications, which have all the technical and technological features needed for work in the tourist facility. Their features allow connection with other departments of the hotel as well as with internal and external reservation systems. This type of software is preferred by hotels with bigger capacity and higher rating. They are updated, taking into account the legislation concerning the work of hotels. The price of the computer products of this class is substantially higher, as is the price of their maintenance.

Concerning the management of the facility, the software is connected with all management functions, including planning (with the newest systems of this type). Its usage leads to automation of the activities in the hotel, so the human factor is partly responsible for the quality of the service, but human activity is mainly restricted to introducing data into the system. The system, in its turn, generates a variety of reference, needed for the management. The whole work and management process is facilitated.

Connecting software - This software is developed specifically for big hotel complexes and hotel chains and takes into consideration all features of the facilities. The specific thing about this software is that, in addition to its local 
function of work, online connection with mediators and reservation systems, it also has a connecting function between the separate facilities within the hotel chain, and i.e. it has a networking function. The price of this kind of software is higher, but the specifics of the work in chains require it.

From a management perspective it can be concluded that the connecting systems are similar to the high-tech ones, apart from the fact that they can receive information about the other hotels from the chain in real time and that they process much bigger information flows.

All three types of computer programs are successfully applied in the hotel facilities survey consisting of 10 key questions. Because the studied facilities were only 5 four-star hotels, it turned out that the research needed to be repeated and more hotels of different rating needed to be included for the information to be more conclusive.

In the period 2013-2016, 47 hotel establishments from 114 that are located in the Veliko Tarnovo region, which were using specialized hotel management software were examined. The analyze of data was accomplished in the period January - March 2017. That number of hotel establishments forms $41.2 \%$ of all hotel establishments in the region. The survey is expanded and includes 18

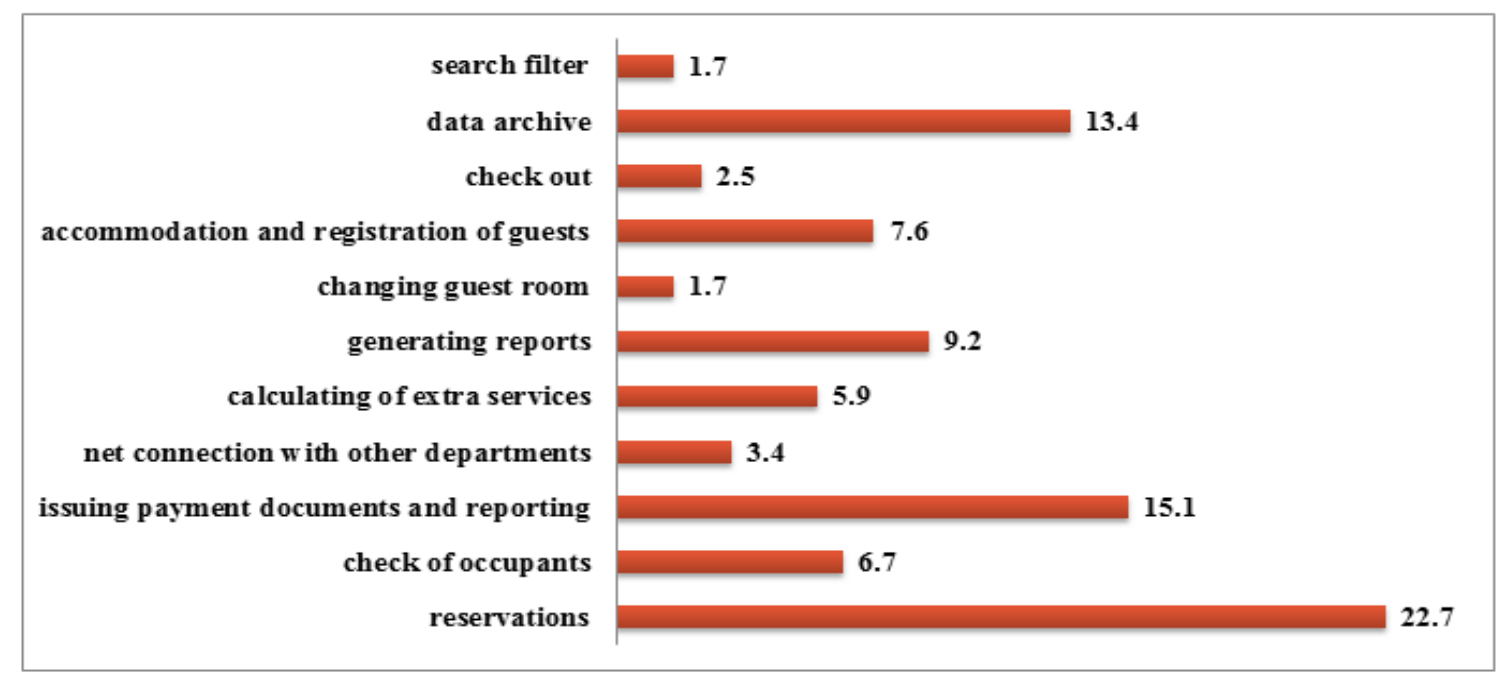

Figure 3. The most important functions according to the managers (in \%)

and help the managers and staff with the performance of their tasks and assist the achieving of management goals.

\section{Research of the role of hotel management software in Veliko Tarnovo region}

The following survey used a questionnaire method to establish the most widely used and preferred hotel programs in Veliko Tarnovo region. In 2011 an attempt was made to establish the role of hotel software in high-class facilities in the destination Veliko Tarnovo - Arbanasi, by means of a questions, divided in 3 categories.

The first category of questions are introducing for the survey (from 1 to 8 question). The second category questions are about technological qualities of the program - advantages disadvantages and functions (from 9 to 15 question). The third category questions are about the grade and recommendation of the hoteliers about improving the activity of the programs (from 16 to 18 question). The collected data from the survey showed that the advantages of the system are much more than the disadvantages and are contributing for the effective functioning of the hotel.

The accent of the survey, that will be presented in the present paper is from the 
second category of questions and is connected with the role of software it the hotel management. According to the managers opinion that took place in the survey the most important are the functions displayed on figure 3 . The collected data shows that the advantages of the systems outnumber by far the disadvantages, thus contributing to the effectiveness of the hotels.

The research answers other questions too, the most important conclusion being that the hotel systems are modernized and updated relatively frequently (almost every year), which means that they are flexible, fully integrated, time and finance saving devices with wide application and at competitive prices.[3]

\section{Conclusion}

Local hotel systems are functional and efficient, with a high management and technological capacity, which makes them some of the most widely used and preferred tools in the hotel business. They improve the working environment at the facility, optimize the working process and reduce the chances for technical and technological mistakes.

\section{References}

[1] Lukanova, G., Problems and Perspectives in the application of software in Bulgarian hospitality, Proceedings on "Technological innovations and tourism of Bulgaria", Publishing House Slavena, Varna, 92-102, 2004.

[2] Mancheva-Ali, O., Maya Nikolova, The Role of the Local Hotel Systems in the Management of High-Class Hotels in the Veliko Tarnovo - Arbanassi Destination, Proceedings "Days of Science", Volume 2, Union of Scientists, Veliko Tarnovo Branch Office, pp. 97-102, 2011.

[3] Todoriev, V., Hotel operations, Sofia, Matkom Publishing House, 2008, 35 p.

[4] Kraeva, V., Introduction to Information Technology, Svishtov, 2012, 14 p. 